\title{
Efeitos da isquemia e da reperfusão na ocorrência de apoptose no jejuno em eqüinos
}

[Effects of ischemia and reperfusion in apoptosis occurrence in equine jejunum]

\author{
J.M.G. Abreu ${ }^{1}$, G.E.S. Alves ${ }^{2 *}$, A.C. Vasconcelos ${ }^{3}$, J.D. Ribeiro Filho ${ }^{4}$, R.R. Faleiros ${ }^{2}$ \\ ${ }^{1}$ Faculdade de Veterinária - UECE, Fortaleza, CE \\ ${ }^{2}$ Escola de Veterinária - UFMG \\ Caixa Postal 567 \\ 30123-970 - Belo Horizonte, MG \\ ${ }^{3}$ Instituto de Ciências Biológicas - UFMG - Belo Horizonte, MG \\ ${ }^{4}$ Departamento de Veterinária - UFV - Viçosa, MG
}

\begin{abstract}
RESUMO
Investigou-se o resultado da isquemia, da congestão e da reperfusão na ocorrência de apoptose. Modelos de obstrução vascular total - artériovenosa e venosa - foram induzidos no jejuno por $2 \mathrm{~h}$, seguidos de reperfusão durante $12 \mathrm{~h}$. As amostras de tecidos foram processadas, e os dados analisados pelo teste de Friedman. As colorações de Schorr e hematoxilina-eosina evidenciaram anoiquia, condensação da cromatina, fragmentação nuclear e celular características de apoptose. Índices apoptóticos significativamente mais baixos ocorreram em $2 \mathrm{~h}$ e $12 \mathrm{~h}$ de reperfusão na região das vilosidades, e tenderam à estabilidade na região das criptas. A apoptose constitui uma importante parcela na perda de células intestinais durante a isquemia, congestão e reperfusão, além da necrose.
\end{abstract}

Palavras-chave: eqüino, apoptose, reperfusão, jejuno

\begin{abstract}
The effects of ischemia and reperfusion in apoptosis occurrence in equine were studied. Intestinal samples were taken and biopsy specimens evaluated. Data were analyzed by Friedman test. Schorr and hematoxilin-eosine staining showed shrunken anoykic cells, chromatin condensation, nuclear and cellular fragmentation typical of apoptosis. Significant lower apoptotic index occurred at $2 \mathrm{~h}$ and $12 \mathrm{~h}$ of reperfusion in the villous region. No difference was observed in the crypt region. Apoptosis constitutes an important part of cell loss in addition to necrosis.
\end{abstract}

Keywords: horse, apoptosis, reperfusion, jejunum

\section{INTRODUÇÃO}

Desde a sua observação no fígado isquêmico (Kerr, 1971), a apoptose tem sido reconhecida em diversos tecidos submetidos à isquemia e reperfusão (I-R) (Li et al., 1995; Gottlieb et al., 1996; Daemen et al., 1999). A função e a viabilidade intestinais podem ser gravemente afetadas, mesmo após períodos curtos de

Recebido em 11 de novembro de 2004

Aceito em 10 de outubro de 2006

*Autor para correspondência (corresponding author)

E-mail: geraldo@vet.ufmg.br

Apoio: FAPEMIG - FUNCAP - UECE. isquemia, sendo que a extensão desses danos depende da duração da alteração circulatória. Nas situações de abdome agudo eqüino, as manobras e intervenções cirúrgicas, necessárias para a correção de distúrbios intestinais, podem ampliar a lesão através do estresse oxidativo gerado durante a reperfusão.

Estudos mostraram que períodos de isquemia tão curtos quanto cinco minutos resultaram no 
aparecimento de corpos apoptóticos durante a subseqüente reperfusão, com mínimo aparecimento de necrose, e elevando-se o tempo de isquemia, as mortes apoptótica e necrótica tornaram-se identicamente proeminentes (Schumer et al., 1992). A oclusão da artéria mesentérica superior, com subseqüente reperfusão, causou lesão e apoptose na mucosa do intestino delgado (Noda et al., 1998; Ikeda et al., 1998) em índices superiores ao da necrose. Shah et al. (1997) investigaram a participação da apoptose após reperfusão do intestino de ratos submetidos a isotransplante, verificando que a apoptose foi a principal forma de morte celular após I-R.

É possível que a apoptose represente um componente real em pacientes com cólica. Segundo Rowe et al. (2003), o número elevado de células apoptóticas em eqüinos com doença gastrintestinal pode ser importante para iniciar inflamação e lesão subseqüente, e índices apoptóticos encontrados em segmentos intestinais distantes da lesão original podem contribuir para íleo paralítico pós-cirúrgico.

Até o presente, a morfologia é o principal meio de identificação da apoptose (Harmon et al., 1998; Reneham et al., 2001). Ao iniciar a apoptose, a célula se torna arredondada e dá início a um processo de separação das células vizinhas normais e da matriz extracelular. Posteriormente, começa a apresentar protusão da membrana plasmática, comumente referida como projeções digitiformes. A interação entre a matriz e as células apresenta importantes efeitos na estrutura do citoesqueleto, diferenciação e aspectos do crescimento celular, e a ruptura dessas interações induz a apoptose (Frisch e Francis, 1994).

O objetivo deste estudo foi determinar os índices apoptóticos no jejuno normal e submetido a períodos de isquemia e reperfusão em eqüinos.

\section{MATERIAL E MÉTODOS}

Foram usados seis eqüinos adultos sob anestesia geral e monitorados, sendo submetidos a dois modelos de obstrução (OBS) vascular simultâneo -hemorrágico e isquêmico- pela interrupção da circulação mural, venosa (OVEN) ou artériovenosa (OARV) com drenos de Penrose. Um terceiro segmento, não submetido à obstrução vascular, permaneceu como controle (CONT). Após duas horas, a circulação foi restabelecida, pela retirada das ligaduras, quando se iniciou a fase de reperfusão (REP), com duração de $12 \mathrm{~h}$. As amostras foram colhidas antes da aplicação das ligaduras $(0 \mathrm{~h})$, e nos tempos de $1 \mathrm{~h}$ e $2 \mathrm{~h}$ na fase de OBS, e $1 \mathrm{~h}, 2 \mathrm{~h}$ e $12 \mathrm{~h}$ na fase de REP. Os fragmentos de tecido foram processados rotineiramente (Luna, 1968), blocados em parafina e seccionados a $5 \mu \mathrm{m}$. As lâminas foram coradas por hematoxilina-eosina e Shorr e analisadas pela microscopia ótica.

As células foram identificadas como apoptóticas quando apresentavam características morfológicas compatíveis (Kerr et al., 1972). Como critérios de inclusão, selecionaram-se aquelas com morfologia típica, com condensação nuclear e citoplasmática ou resíduos citoplasmáticos contendo densos fragmentos de cromatina, retração e perda da aderência entre as células (anoiquia) e membrana basal, formando os corpos apoptóticos. Somente as células (apoptóticas ou normais) que permaneciam unidas à região das vilosidades e criptas foram incluídas para determinação do índice. Enterócitos que sofreram exfoliação, desprendimento e com características de necrose não foram quantificados.

O índice apoptótico (IA) para a região das vilosidades ou criptas foi determinado dividindose o número de células apoptóticas pelo número de células totais ao longo do eixo vilosidade ou cripta, e multiplicado por 100 (Vasconcelos, 1994). Levou-se em consideração a média dos IA determinados em três vilosidades ou em três campos da região das criptas por seção (400X).

Nas comparações entre os três segmentos, em cada tempo em relação às medidas do IA vilosidade e do IA na cripta, foi utilizado o teste de Friedman. Os resultados foram considerados significativos ao nível de 5\%.

\section{RESULTADOS}

Os resultados dos IA nas vilosidades e criptas estão apresentados nas Tab. 1 e 2. Nos exames microscópicos dos segmentos experimentais, a maior parte das observações dos eventos apoptóticos foi na forma ativa, com células 
mostrando marginação da cromatina nuclear proeminente, enrugamento citoplasmático, anoiquia, fragmentação nuclear e corpos apoptóticos fagocitados. Nos tempos mais avançados, a atividade apoptótica foi principalmente na forma de fragmentos citoplasmáticos e nucleares fagocitados no epitélio. Moderada atividade apoptótica de enterócitos no lume intestinal foi evidenciada.

Tabela 1. Médias dos índices apoptóticos (IA) nas vilosidades dos segmentos intestinais experimentais em função do tempo

\begin{tabular}{lccc}
\hline Tempo / Segmento & SCONT* & SOVEN*** & SOARV** \\
\hline Oh & $22,4 \mathrm{aA}$ & $22,4 \mathrm{aA}$ & $22,4 \mathrm{aA}$ \\
1h OBS & $18,2 \mathrm{aAB}$ & $19,7 \mathrm{aA}$ & $17,1 \mathrm{aA}$ \\
2h OBS & $17 \mathrm{aB}$ & $18,4 \mathrm{aA}$ & $15,6 \mathrm{aA}$ \\
1h REP & $16,1 \mathrm{aB}$ & $19,1 \mathrm{aA}$ & $18,2 \mathrm{aA}$ \\
2h REP** & $16,8 \mathrm{aB}$ & $14,9 \mathrm{bB}$ & $11,2 \mathrm{cB}$ \\
$12 \mathrm{~h} \mathrm{REP} *$ & $16,6 \mathrm{aB}$ & $12,3 \mathrm{bB}$ & $12,3 \mathrm{bB}$ \\
\hline
\end{tabular}

Valores seguidos por letras minúsculas na linha (entre segmentos em cada tempo) ou maiúsculas (entre tempos em cada segmento) na coluna diferem entre si.

Na linha: * $\mathrm{P}<0,03 ; * * \mathrm{P}<0,006$.

Na coluna: $* \mathrm{P}<0,04 ; * * \mathrm{P}<0,004 ; * * * \mathrm{P}<0,002$.

$\mathrm{O}$ valor de P refere-se ao teste Friedman; SCONT= controle; SOVEN= obstrução venosa; SOARV= obstrução arteriovenosa.

Tabela 2. Médias dos índices apoptóticos (IA) nas criptas dos segmentos intestinais experimentais em função do tempo

\begin{tabular}{lccc}
\hline Tempo / Segmento & SCONT & SOVEN* & SOARV \\
\hline Oh & $5,3 \mathrm{aA}$ & $5,3 \mathrm{aA}$ & $5,3 \mathrm{aA}$ \\
1h OBS & $4,0 \mathrm{aA}$ & $3,8 \mathrm{aB}$ & $2,9 \mathrm{aA}$ \\
2h OBS & $4,5 \mathrm{aA}$ & $3,8 \mathrm{aB}$ & $3,3 \mathrm{aA}$ \\
1h REP & $4,2 \mathrm{aA}$ & $4,7 \mathrm{aA}$ & $3,7 \mathrm{aA}$ \\
2h REP & $3,5 \mathrm{aA}$ & $3,3 \mathrm{aB}$ & $2,7 \mathrm{bA}$ \\
12h REP & $4,3 \mathrm{aA}$ & $3,4 \mathrm{aB}$ & $3,8 \mathrm{aA}$ \\
\hline
\end{tabular}

Valores seguidos por letras minúsculas na linha (entre segmentos em cada tempo) ou maiúsculas (entre tempos em cada segmento) na coluna diferem entre si.

Na linha e na coluna $* \mathrm{P}=0,04$

O valor de P refere-se ao Teste Friedman; SCONT= controle; SOVEN= obstrução venosa; SOARV= obstrução arteriovenosa.

\section{DISCUSSÃO}

Embora seja reconhecida a sensibilidade da mucosa intestinal a I-R, a dimensão da apoptose nesse processo em eqüinos é desconhecida. A presente pesquisa permitiu estudar a ocorrência desse mecanismo de eliminação celular no jejuno normal de eqüinos e verificar a dinâmica de sua apresentação em períodos de isquemia e congestão, seguida de reperfusão. Essa alteração circulatória simula a clínica de abdome agudo com estrangulamento vascular grave. Os autores que estudaram o fenômeno de I-R natural ou experimentalmente em eqüinos têm atribuído a morte celular do epitélio intestinal exclusivamente à necrose. Contudo, verificou-se que a apoptose ocorre em taxas fisiológicas, sendo também desencadeada por várias agressões, incluindo as circulatórias.

O presente estudo permitiu confirmar o fenômeno da apoptose como componente da lesão de I-R intestinal em eqüinos e a evidência para seu envolvimento foi dada pelas características morfológicas, conforme descritas em critérios de inclusão (Kerr et al., 1972). Essa forma de morte celular só foi caracterizada morfologicamente no ID durante I-R recentemente (Shah et al., 1997) em ratos transplantados, e o atual estudo é, provavelmente, o primeiro a caracterizar o processo em eqüinos in vivo, no jejuno normal e após obstrução vascular seguida de reperfusão experimentais. 
Apesar de existirem vários testes sofisticados para detecção de apoptose, a principal forma de identificação é a que utiliza critérios morfológicos (Harmon et al., 1998; Reneham et al., 2001). A metodologia empregada no atual trabalho utilizando microscopia ótica em seções coradas por hematoxilina-eosina e Schorr mostrou-se satisfatória para identificação de células apresentando anoiquia, condensação nuclear, condensação citoplasmática e corpos apoptóticos.

É possível que o período de jejum alimentar dos eqüinos tenha favorecido a ocorrência de apoptose, refletindo-se em elevação fisiológica no IA do tempo basal (Iwakiri et al., 2001), e essa observação necessita de estudos mais aprofundados. A cinética de evolução da apoptose nas vilosidades dos segmentos OVEN e segmentos OARV em função do tempo demonstrou um comportamento semelhante, ou seja, permaneceu estável durante a fase congestiva ou isquêmica e início da reperfusão e diminuiu significativamente nos tempos subseqüentes de reperfusão. Estes resultados são diferentes dos encontrados por Noda et al. (1998) que verificaram elevação do IA durante a primeira hora de isquemia intestinal, que continuou aumentando durante a hora seguinte de reperfusão. Esses autores levaram em consideração, na quantificação, células com características de apoptose que se desprenderam das vilosidades frente aos distúrbios vasculares provocados, localizando-se no lume, o que não ocorreu na presente pesquisa.

Ikeda et al. (1998), ao realizarem inclusão de células intestinais desprendidas na determinação do IA, verificaram que a apoptose foi a principal forma de perda celular em I-R. A razão para essa cinética de morte celular programada e recuperação do epitélio parece estar relacionada com o aumento do tempo, que depende de fatores promotores da apoptose durante a isquemia e fases iniciais da reperfusão, que diminui bruscamente durante a reperfusão prolongada. Em seguida deve ocorrer liberação de promotores da reparação tecidual.

Shah et al. (1997), ao estudarem a participação da apoptose em modelo de I-R intestinal em ratos, verificaram que a observação dos eventos apoptóticos nas vilosidades ficou prejudicada durante a reperfusão, uma vez que ocorreu desintegração progressiva da estrutura da mucosa. Embora graus discretos de lesão na mucosa intestinal permitam a quantificação adequada do IA, lesões com escores $\geq 3$ tornaram difícil a avaliação desse valor (Farber et al., 1999). A mesma limitação foi encontrada na avaliação das seções na atual pesquisa. Os dois últimos tempos de reperfusão ( $2 \mathrm{~h}$ e $12 \mathrm{~h}$ ) mostraram uma diminuição dos IA nas vilosidades, o que pode indicar período de regeneração da mucosa intestinal, quando a apoptose deve cessar, elevando-se a proliferação de células normais.

Nesta pesquisa, verificou-se a distribuição da apoptose na mucosa intestinal. Escolheram-se dois locais para observação (criptas e vilosidades). Alguns autores anteriormente demonstraram a ocorrência de apoptose em diferentes regiões do eixo vilosidade/cripta (Hall et al., 1994). Potten et al. (1997), ao estudarem a ocorrência da apoptose no ID de humanos e ratos, verificaram que a apoptose espontânea ocorria predominantemente nas regiões mais inferiores das criptas. Segundo esses autores, esse controle na região das células tronco é fundamental para manter o nível de migração celular da cripta para vilosidade.

Esta pesquisa confirmou os resultados de estudos anteriores de que o intestino delgado é bastante sensível a insultos vasculares. Os graus das lesões são tempo dependente e iniciam-se na extremidade das vilosidades e progridem em direção às criptas. As células da região apical das vilosidades situam-se em um grau avançado de diferenciação, já tendo cumprido sua função, dessa forma, estão mais propensas a ativarem o programa apoptótico como parte normal de seu ciclo. Os outros enterócitos, da região medial das vilosidades e das criptas, permanecem por mais tempo, pois são responsáveis pela recomposição estrutural da mucosa (Hinnebusch et al., 2002). A diferença entre os IA nas regiões das vilosidades e criptas sugere que a apoptose é regulada independentemente em cada região. Isso pode estar relacionado com a distribuição de genes reguladores no eixo vilosidade/cripta. O fenômeno de isquemia e reperfusão intestinal representa um importante campo de investigação visando à compreensão da apoptose. Verifica-se, assim, uma possível abordagem terapêutica para proteger o ID de lesões de I-R, ou seja, manutenção de células epiteliais em estado 
indiferenciado, durante e após a intervenção cirúrgica de abdome agudo.

Este trabalho demonstrou a ocorrência de apoptose, além da eliminação por necrose, muitas vezes classificada como o único mecanismo de morte celular, em ambas as fases da I-R. A diferenciação entre os dois fenômenos é importante, pois o clássico evento da necrose ocorre passivamente ao acaso, enquanto apoptose envolve genes regulatórios, transdução de sinais e efetores bioquímicos. O aprofundamento dos estudos nessa área poderá refletir-se na elaboração de estratégias terapêuticas que modulem o processo, evitando lesões mais graves. As drogas a serem desenvolvidas provavelmente terão ação limitada nas células que foram gravemente lesadas por mediadores da I-R, mas podem ser de valia para as células remanescentes, em processo de apoptose, pois são elas que têm o potencial de recuperação.

Clinicamente, a ajuda a certas populações celulares pode ser significante, em termos de preservação da função intestinal e dos efeitos sistêmicos da lesão. Intervenção sobre a morte celular em síndromes isquêmicas do intestino, tal como ocorre em pacientes com abdome agudo, pode não só diminuir a extensão do segmento de intestino inviável a ser removido cirurgicamente, como também afetar a gravidade da resposta inflamatória sistêmica que acompanha I-R. Não foi possível estabelecer as relativas contribuições entre necrose e apoptose, contudo a morte celular programada parece participar de uma parcela importante na perda de células intestinais durante a I-R.

\section{CONCLUSÕES}

A apoptose ocorre em condições fisiológicas em enterócitos do jejuno de eqüinos, variando seu índice ao longo do eixo vilosidades/criptas, sendo maior na região distal e média das vilosidades e menor na região das criptas. No jejuno normal, o IA apresenta variações fisiológicas nas vilosidades e criptas, tendendo à estabilização. A apoptose nas vilosidades dos segmentos OARV e OVEN mantém seu índice estabilizado até a primeira hora de reperfusão, diminui em seguida e retorna à estabilidade durante as horas seguintes ( $2 \mathrm{~h}$ e $12 \mathrm{~h}$ ); a apoptose nas criptas dos segmentos OARV e OVEN mantém seu índice com tendência à estabilização durante as fases de isquemia, congestão e reperfusão.

\section{REFERÊNCIAS BIBLIOGRÁFICAS}

DAEMEN, A.R.C.; VAN'T VEER, C.; DENECKER, G. et al. Inhibition of apoptosis induced by ischemia reperfusion prevents inflammation. J. Clin. Inv., v.104, p.541-549, 1999.

FARBER, A.; CONNORS, J.P.; FRIEDLANDER, R.M. et al. A specific inhibitor of apoptosis decreases tissue injury after intestinal ischemia reperfusion in mice. J. Vasc. Surg., v.30, p.752-760, 1999.

FRISCH， S.M.; FRANCIS, H. Disruption of epithelial cell matrix interactions induces apoptosis. J. Cell Biol., v.124, p.619-626, 1994.

GOTTLIEB, R.A.; GRUOL, D.L.; ZHU, J.Y. et al. Preconditioning rabbit cardiomyocytes: role of $\mathrm{pH}$, vacuolar proton ATPase, and apoptosis. J. Clin. Invest., v.97, p.2391, 1996.

HALl, P. A.; COATES, P. J.; ANARI, B. et al. Regulation of cell number in the mammalian gastrointestinal tract. The importance of apoptosis. J. Cell Sci., v.107, p.3569-3577, 1994.

HARMON, B.V.; WINTERFORD, C.M.; O'BRIEN, B.A. et al. Morphological criteria for identifying apoptosis. In: CELIS, J.E. (Ed). Cell biology: A laboratory handbook. 2.ed. San Diego: Academic, 1998. v.1, p.327-356.

HINNEBUSCH, B.F.; MA, Q.; HENDERSON, J.W. et al. Enterocyte response to ischemia is dependent on differentiation state. J. Gastrointest. Surg., v.6, p.403-409, 2002.

IKEDA, H.; SUZUKI, Y.; SUZUKI, M. et al. Apoptosis is a major mode of cell death caused by ischemia and ischemia reperfusion injury to the rat intestinal epithelium. Gut, v.42, p.530-537, 1998.

IWAKIRI, R.; GOTOH, Y.; NODA, T. et al. Programmed cell death in rat intestine: effect of feeding and fasting. Scand. J. Gastroenterol., v.36, p.39-47, 2001.

KERR, J.F. Shrinkage necrosis: a distinct form mode of cellular death. J. Pathol., v.105, p.13, 1971.

KERR, J. F.; WYLlIE, A. H.; CURRIE, A. R. Apoptosis: a basic biological phenomenon with wide ranging implications in tissue kinetics. $B r . J$. Cancer, v.26, p.239, 1972. 
LI, Y.; CHOPP, M.; JIANG, N. et al. Induction of DNA fragmentation after 10 to 120 minutes of focal cerebral ischemia in rats. Stroke, v.26, p.1252, 1995.

LUNA, L.G. Manual of histologic staining methods of the Armed Force Institute of Pathology. 3.ed. New York: McGraw Hill, 1968.

NODA, T.; IWAKIRI, R.; FUJIMOTO, K. et al. Programmed cell death induced by ischemia reperfusion in rat intestinal mucosa. Am. J. Physiol., v.37, p.G270-G276, 1998.

POTTEN, C.S.; WILSON, J.W.; BOOTH, R. Regulation and significance of apoptosis in stem cells of the gastrointestinal epithelium. Stem Cells, v.15, p.82-93, 1997.

RENEHAM, A.G.; BOOTH, C.; POTTEN, C.S. What is apoptosis and why is it important? Br. Med. $J .$, v.322, p.1536-1538, 2001.
ROWE, E.L. Detection of apoptotic cells in intestine from horses with and without gastrointestinal disease. 2003. 98f. Thesis (Master of Science) - Virginia Polytecnic Institute and State University, Virginia.

SCHUMER, M.; COLOMBEL, M.C.; SAWCZUK, $\mathrm{S}$. et al. Morphologic, biochemical, and molecular evidence of apoptosis during the reperfusion phase after brief periods of renal ischemia. Am. J. Pathol., v.140, p.831-838, 1992.

SHAH, K.A.; SHUREY, S.; GREEN, C.J. Apoptosis after intestinal ischemia reperfusion injury; a morphological study. Transplant, v.64, p.1393-1397, 1997.

VASCONCELOS, A.C. Virus-induced apoptosis in avian lymphoid tissues. 1994. 134f. Thesis (PhD) University of Califórnia, Davis, CA. 